\title{
Computer-Aided Teaching Using Animations for Engineering Curricula: A Case Study for Automotive Engineering Modules
}

\author{
Pedram Asef ${ }^{(0)}$, Senior Member, IEEE, and Christos Kalyvas
}

\begin{abstract}
One-dimensional (1-D) demonstrations, e.g., the black-box systems, have become popular in teaching materials for engineering modules due to the high complexity of the system's multidimensional (e.g., 2-D and 3-D) identities. The need for multidimensional explanations on how multiphysics equations and systems work is vital for engineering students, whose learning experience must gain a cognitive process understanding for utilizing such multiphysics-focused equations into a pragmatic dimension. The lack of knowledge and expertise in creating animations for visualizing sequent processes and operations in academia can result in an ineffective learning experience for engineering students. This study explores the benefits of animation, which can eventually improve the teaching and student learning experiences. In this article, the use of computer-aided animation tools is evaluated based on their capabilities. Based on their strengths and weaknesses, the study offered some insights for selecting the investigated tools. To verify the effectiveness of animations in teaching and learning, a survey was conducted for undergraduate and postgraduate cohorts and automotive engineering academics. Based on the survey's data, some analytics and discussion have offered more quantitative results. The historic data (2012-2020) analysis has validated the animations efficacy as achievements of the study, where the average mark of both modules has significantly improved, with the reduced rate of failure.
\end{abstract}

Index Terms-Animation, automotive engineering (AE), computer-aided software, courseware, curriculum development, educational technology, engineering education, statistics, STEM.

\section{INTRODUCTION}

$\mathbf{T}$ ODAY, state of engineering and science maturity and complexity is ahead of the knowledge required to improve the teaching presentations in the engineering curriculums [1]. For example, most of the multidisciplinarian content taught in automotive engineering (AE) modules need 2-D and 3-D animations for explaining better how multiphysics equations and systems actually work. This gains a cognitive process dimension for utilizing such multiphysics-focused equations into the pragmatic dimension.

Manuscript received January 31, 2021; revised May 9, 2021; accepted July 25, 2021. (Corresponding author: Pedram Asef.)

The authors are with the Automotive Engineering Group, Department of Engineering, University of Hertfordshire, Hatfield AL10 9AB, U.K. (e-mail: p.asef@herts.ac.uk; c.kalyvas@herts.ac.uk).

This article has supplementary downloadable material available at https://doi.org/10.1109/TE.2021.3100471, provided by the authors.

Digital Object Identifier 10.1109/TE.2021.3100471
Such a knowledge transfer is traditionally delivered using diagrams, flowcharts, schematics (1-D), and analytical equations in the classrooms. To improve the knowledge transfer satisfaction, traditionally, most often the lectures also present the technical information in the laboratories, workshops, or even classrooms. The practical learning experience helps developing industrial insights, which may be validating the analytical and numerical-based concepts discussed in the classrooms. Still, developing a learner's cultivating capacity highly depends on a deep understanding of how actually the process happens. To deliver such highly engineered computer-aided presentations to demonstrate such complex systems, the impact of visualization and animations is unavoidable [2], [3].

The researchers [4] have analyzed the effects of interactive animations in teaching, based on the student's performance. They have verified the effectiveness of using animations in the classroom by grouping the students, one group with traditional teaching materials, and the second group has benefited from the animations as a supplementary tool. From the final exams, they statistically proved that the second group has significantly performed better and finally received higher marks. In another valuable study, the investigators have [3] concluded that the students with provided supplementary animations on two questions have performed better than the other group of students by $50 \%$ and $38 \%$. In [5], the research has focused on the effects of using animations to observe the student learning experience during an engineering microprocessing module. By their survey in 2006 , the students responded by $94 \%$ that the animations could well or very well deliver the objectives of the course, where surprisingly above $72 \%$ have reported that the proposed teaching was either more or much more effective compared to the factual experience such as laboratories in demonstrating the procedural concepts.

The advantages of providing multimedia-oriented materials in the teaching presentations have been investigated using a blended learning approach [6]. They have reported that the student's marks increased for engineering master's degree modules, such as programming fundamentals I and II. To evaluate the role of multimedia in teaching quality [7], this quantitative-focused work has defined some evaluation indicators, such as teaching attitude, teaching content, teaching ability, and teaching organization and media. Finally, they employed a genetic algorithm to analyze the proposed formula based on those indices, to compute the quality of multimedia teaching in the college. 


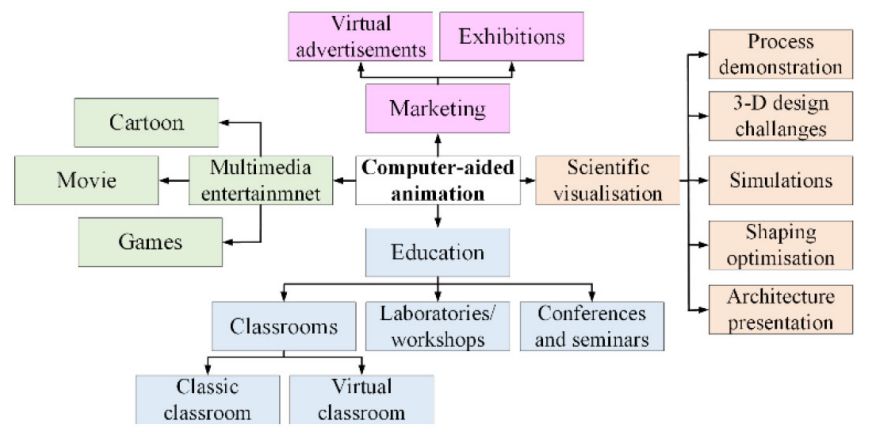

Fig. 1. Computer-aided animation tool classification.

The impact of interactive visualizations and animation-aided learning outcomes has been discovered [8]-[10]. However, because of the lack of needed skills for creating such multimedia-based teaching presentations [11], most of the academics neglect to design and use such teaching materials. In different engineering disciplines, the use of animations was recently focused in the curriculums, see [5], [12]-[14].

The insufficiency of knowledge and guidelines on how to benefit from the computer-aided tools requires a culture building in higher education (HE) systems [15], [16]. The challenge becomes more critical when it is compulsory to shift to partially or completely online learning platforms [17]. In this study, the evaluation of animation tools helps to identify the capabilities and knowledge required to enhance the teaching contents. For enabling any HE institutes to benefit from these advances, a new culture building is needed. In Fig. 1, the applications of animation are illustrated, where the education-related use, such as classrooms, laboratories and workshops, and conference and seminars are considerable for such a culture building. This inspirational graph is produced from animations designed within different industries.

The fact that some HE environments are underprivileged of having their regular standard face-to-face teaching systems [18] during the universities closure, i.e., COVID-19 pandemic, are enormous. Due to the lack of interactive online content quality and accessibilities, if the blended or fully online learning is to succeed [19]. Martínez et al. [20] have presented how the learning experience for an online group in an engineering master's degree program, which has previously been offered as traditional face-to-face learning. They discuss how the transformational learning environments have been affected in terms of interaction, enrolment, satisfaction index and dropout rate, and final grades.

To improve conventional engineering teaching materials, where they are more interactive, the use of multimedia, visualization, and animation is vital. Animation creation: there is a lack of information and guidelines on what are available tools, including essential (or core) and commercial types, to employ for creating practical animations and visualization in engineering modules. The question is what computer-aided tools are today available for engineering concepts, considering the level of design complexity is going to be explored. The article is focused on exploring the animation tools to enable students to take advantage of better teaching materials. Introducing the recent animation tools, their capabilities, and knowledge required to use them will help engineering academics to be encouraged to utilize more visualizations in their teaching materials, most of the computer-aided interactive animation tools and their capabilities are evaluated in this article. Finally, the effectiveness of using animations is evaluated among the students of two AE modules, entitled Automotive Electrical Systems, for undergraduate and postgraduate programs. A similar survey is released among the AE academics, at the University of Hertfordshire. Finally, the collected results and analytics discussed within the appropriate pedagogy are offered to make some conclusions.

\section{CAPABility AnAlysis of COMPUter-Aided ANIMATION TOOLS FOR ENGINEERING CURRICULA}

This section introduces and explores essential and commercial tools for both illustrative and interactive animations. Most of the tools can support similar features such as procedural, behavioral, and motion capturing capability. The procedural techniques depend on a set of predefined rules that are utilized to animate the designed or drawn component. As most of the automotive components deal with multiple operating modes, therefore, several sets of rules are required to demonstrate the movements and different working modes. In behavior techniques, the modes and movements of the part or object are characterized by themselves, which enable them to become improvable by time. This type of techniques eases the animation designer from the storyboards and defining every single movement. In motion capturing (or visual effects) animations, the computer utilizes the real-life motion footages of the components through cameras and tags. The captured motions will be replicated to animate the modeled static object. These features can be categorized as the illustrative type of animations because of the absence of the third-person involvements to change/modify the next moves or modes of animation.

A more sophisticated type of animations is defined as interactive animations in this article, where the interaction of the user (student interface) can change the way the animation flows. These interactions can be done using a mouse, keyboard, pointers, and even virtual reality. Such interactivity may also be categorized as animation gaming. For a better understanding of hybrid electric vehicles (HEVs), for example, an animation of a hybrid electric passenger vehicle can be produced. The power flow of the vehicle can be monitored based on several predesigned conditions, such as driving behavior and/or road conditions, that the students can select. Once the road gradient increases, the student can virtually observe how the power flows instantly in the powertrain between the internal combustion engine (ICE) and electric machines. Such examples allow the students to build a better intuitive and cognitive understanding of the automotive systems.

A capability-based analysis is provided for the introduced producing and prototyping techniques, which are enabled to create engineering objects and components for animation and visualization purposes. The animations are classified into two main groups: 1) illustrative and 2) interactive. Both types of animations can be produced using coding or commercial software. It is worthy to mention that all interactive platforms are 


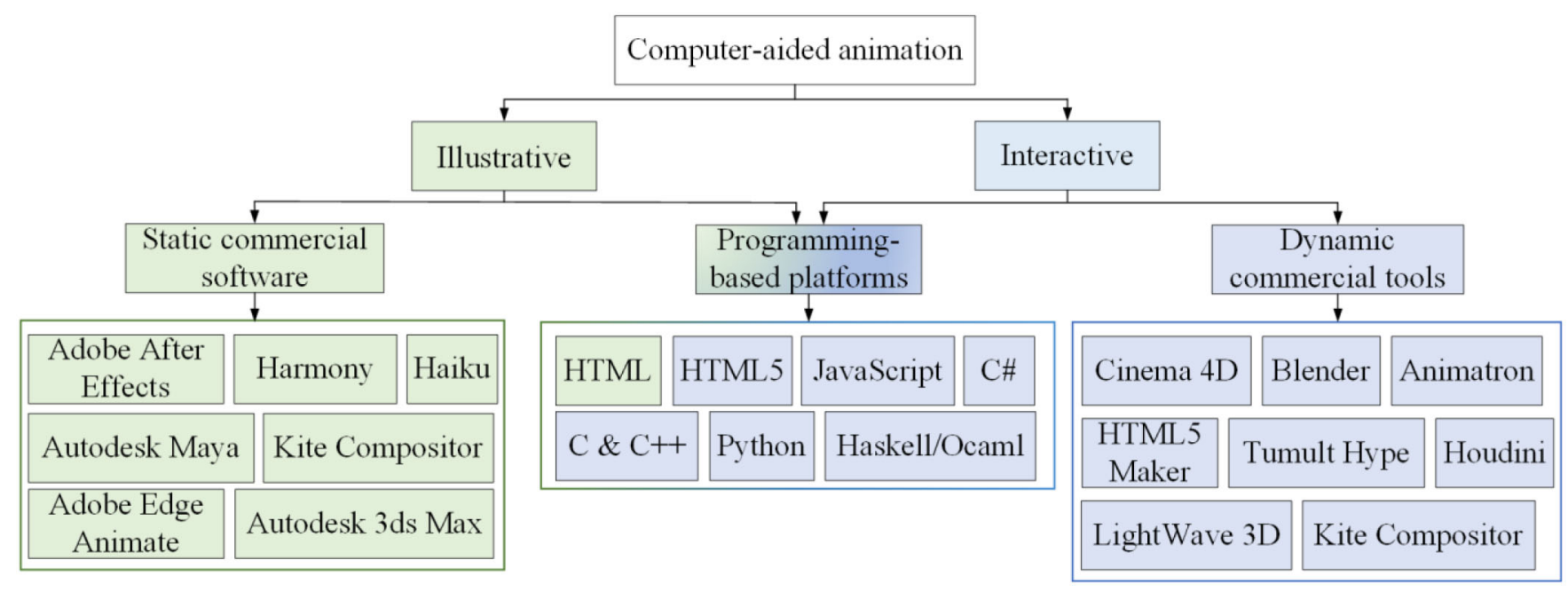

Fig. 2. Computer-aided illustrative and interactive animation tools.

TABLE I

CAPABILITY ANALYSIS OF ILLUSTRATIVE ANIMATION TOOLS

\begin{tabular}{|c|c|c|c|c|c|c|c|c|}
\hline Tools/Features & $\begin{array}{l}\text { Animation } \\
\text { fidelity }\end{array}$ & $\begin{array}{l}\text { Support } \\
\text { quality }\end{array}$ & $\begin{array}{l}\text { Tool } \\
\text { costing }\end{array}$ & Visual effects & $\begin{array}{l}\text { 3-D } \\
\text { capability }\end{array}$ & $\begin{array}{l}\text { Workflow } \\
\text { integration }\end{array}$ & $\begin{array}{l}\text { Design } \\
\text { capability }\end{array}$ & $\begin{array}{l}\text { Difficulty } \\
\text { level }\end{array}$ \\
\hline $\begin{array}{l}\text { HTML } \\
\text { Adobe After Effects } \\
\text { Harmony } \\
\text { Autodesk Maya } \\
\text { Autodesk 3ds Max } \\
\text { Adobe Edge Animate } \\
\text { Kite Compositor } \\
\text { Haiku }\end{array}$ & $\begin{array}{c}\text { medium } \\
\text { very high } \\
\text { very high } \\
\text { high } \\
\text { high } \\
\text { medium } \\
\text { medium } \\
\text { medium }\end{array}$ & $\begin{array}{c}\text { high } \\
\text { high } \\
\text { very high } \\
\text { medium } \\
\text { medium } \\
\text { high } \\
\text { high } \\
\text { high }\end{array}$ & $\begin{array}{c}\text { O.S. } \\
\text { low } \\
\text { medium } \\
\text { high } \\
\text { high } \\
\text { low } \\
\text { low } \\
\text { low }\end{array}$ & $\begin{array}{l}\text { medium } \\
\text { very high } \\
\text { very high } \\
\text { high } \\
\text { very high } \\
\text { low } \\
\text { low } \\
\text { low }\end{array}$ & $\begin{array}{l}\text { low } \\
\text { low } \\
\text { high } \\
\text { high } \\
\text { very high } \\
\text { low } \\
\text { low } \\
\text { low }\end{array}$ & $\begin{array}{c}\text { very high } \\
\text { high } \\
\text { medium } \\
\text { very high } \\
\text { very high } \\
\text { medium } \\
\text { low } \\
\text { very high }\end{array}$ & $\begin{array}{c}\text { high } \\
\text { high } \\
\text { medium } \\
\text { very high } \\
\text { very high } \\
\text { low } \\
\text { medium } \\
\text { medium }\end{array}$ & $\begin{array}{c}\text { very high } \\
\text { low } \\
\text { low } \\
\text { high } \\
\text { high } \\
\text { low } \\
\text { low } \\
\text { low }\end{array}$ \\
\hline
\end{tabular}

also enabled to produce illustrative animations. In Fig. 2, the animation techniques and platforms are introduced, based on the authors' experience and extensive reviews in the related field. The green boxes demonstrate the illustrative animation tools (such as Adobe After Effects, Autodesk Maya, etc.). Whereas, the blue boxes indicate the interactive tools, such as Blender, Cinema 4-D, among others. The programming-based box with green/blue colors presents the coding tools, in which most of them can produce interactive and dynamic animations. Although all the programming tools are free of cost, the coding skills are required. On the other hand, the commercial static and dynamic tools can be costly; however, they offer userfriendly environments. More importantly, they do not require any knowledge of computer programming and some of them offer predefined objects and online tutorials which are very helpful for beginners to produce animations.

Table I exhibits the capabilities of both commercial and programming-based tools, based on the researchers' experience and technical review. The hypertext markup language (HTML) uses cascading style sheets (CSS) to enable HTML codes to be displayed on the screens. To do this, other tools like JavaScript (or JS), Canvas, scalable vector graphics, and, WebGL-based are employed for the same purpose, however, the CSS due to its capacities to work with the graphic processing unit of the computers for graphics acceleration, is proposed. The HTML can produce very high fidelity and dynamic animations, where also 3-D visualizations are reachable with limitations and programming complications. Another significant advantage of using this programming technique is being free. The popular Adobe After Effects software, which is used to produce for example the formula 1 animation [21], is shown among commercial tools. The main advantage of the tool is its visual effects and easy-to-use or level of difficulty for the animator. The software offers very high-fidelity animations with excellent user-friendly features. The Harmony tool is another powerful tool for illustrative animation productions, they are popular for the visual effects, 3-D design capability, and high-rated level of support satisfaction by the users. The Autodesk package tools, Maya and 3ds Max are both used for animation production. They benefit from the 2-D/3-D design capabilities of the software which earlier were utilized only for CAD designing. Therefore, a high degree of freedom in design is available, however, mostly the tools are employed by the users familiar with the CAD designs. The opensource powerful tool, Blender, is very well known, free-to-use classic animation tool. This tool offers very high animations in both 2-D and 3-D, and the visual effects are the best for vehicle dynamic systems demonstrations due to soft/rigid body visual effects, fire and smoke for many ICE and exhaust unit modeling. Since the tool is out for a long time, there are many online tutorials and materials available to learn the tool for beginners. Also, the Adobe Edge Animate is another Adobe product with animation creation capability, which has lower animation fidelity, design, and performance in comparison with Adobe After Effects. The Kite Compositor and Haiku tools are popular for simple animations with ease 
TABLE II

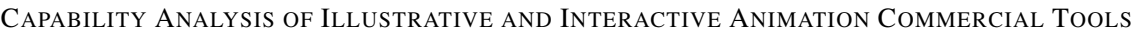

\begin{tabular}{|c|c|c|c|c|c|c|c|c|}
\hline Tools/ Features & $\begin{array}{c}\text { Animation } \\
\text { fidelity }\end{array}$ & $\begin{array}{c}\text { Support } \\
\text { quality }\end{array}$ & $\begin{array}{c}\text { Tool } \\
\text { costing }\end{array}$ & $\begin{array}{l}\text { Visual } \\
\text { effects }\end{array}$ & $\begin{array}{c}\text { 3-D } \\
\text { capability }\end{array}$ & $\begin{array}{l}\text { Workflow } \\
\text { integration }\end{array}$ & $\begin{array}{c}\text { Design } \\
\text { capability }\end{array}$ & $\begin{array}{c}\text { Difficulty } \\
\text { level }\end{array}$ \\
\hline $\begin{array}{l}\text { Cinema 4D } \\
\text { Blender } \\
\text { Houdini } \\
\text { LightWave 3D } \\
\text { Animatron } \\
\text { Tumult Hype }\end{array}$ & $\begin{array}{l}\text { very high } \\
\text { very high } \\
\text { very high } \\
\text { high } \\
\text { high } \\
\text { high }\end{array}$ & $\begin{array}{l}\text { very high } \\
\text { very high } \\
\text { very high } \\
\text { medium } \\
\text { high } \\
\text { high }\end{array}$ & $\begin{array}{l}\text { high } \\
\text { O.S. } \\
\text { very high } \\
\text { medium } \\
\text { very low } \\
\text { low }\end{array}$ & $\begin{array}{l}\text { very high } \\
\text { very high } \\
\text { very high } \\
\text { high } \\
\text { low } \\
\text { medium }\end{array}$ & $\begin{array}{l}\text { very high } \\
\text { very high } \\
\text { very high } \\
\text { high } \\
\text { low } \\
\text { low }\end{array}$ & $\begin{array}{l}\text { very high } \\
\text { very high } \\
\text { very high } \\
\text { high } \\
\text { very high } \\
\text { very high }\end{array}$ & $\begin{array}{l}\text { very high } \\
\text { very high } \\
\text { high } \\
\text { high } \\
\text { medium } \\
\text { high }\end{array}$ & $\begin{array}{c}\text { low } \\
\text { high } \\
\text { medium } \\
\text { low } \\
\text { low } \\
\text { low }\end{array}$ \\
\hline
\end{tabular}

TABLE III

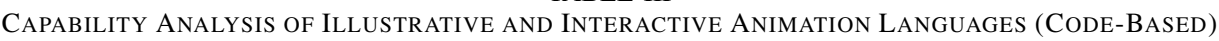

\begin{tabular}{|c|c|c|c|c|c|}
\hline Features/ Languages & $\mathrm{C} / \mathrm{C}++$ & $\mathrm{C \#}$ & JS & HTML5 & Python \\
\hline $\begin{array}{l}\text { Animation fidelity } \\
\text { Support quality } \\
\text { Tool costing } \\
\text { Visual effects } \\
\text { 3-D capability } \\
\text { Workflow integration } \\
\text { Design capability } \\
\text { Difficulty level }\end{array}$ & $\begin{array}{l}\text { medium } \\
\text { high } \\
\text { O.S. } \\
\text { low } \\
\text { medium } \\
\text { very high } \\
\text { high } \\
\text { very high }\end{array}$ & $\begin{array}{l}\text { medium } \\
\text { high } \\
\text { O.S. } \\
\text { low } \\
\text { medium } \\
\text { very high } \\
\text { high } \\
\text { very high }\end{array}$ & $\begin{array}{l}\text { high } \\
\text { high } \\
\text { O.S. } \\
\text { high } \\
\text { high } \\
\text { very high } \\
\text { very high } \\
\text { very high }\end{array}$ & $\begin{array}{l}\text { medium } \\
\text { high } \\
\text { O.S. } \\
\text { low } \\
\text { low } \\
\text { very high } \\
\text { high } \\
\text { very high }\end{array}$ & $\begin{array}{l}\text { high } \\
\text { very high } \\
\text { O.S. } \\
\text { medium } \\
\text { medium } \\
\text { very high } \\
\text { high } \\
\text { very high }\end{array}$ \\
\hline
\end{tabular}

of use for the animators. Both tools also offer considerable support quality.

Table II presents the animation tools which can be used for both illustrative and interactive types of animations. The Cinema 4-D tool is proposed for its professional (particularly by flip fluid add-ons), ICE (fire effects), and smoke visualizations. For simple animation productions (mainly in 2-D), the commercial tools, such as Animatron and Tumult Hype tools are proposed. Animation production and very highperformance capabilities, which even can be more boosted by using more recent add-ons like $x$-particles. This tool also is exceptional for its fantastic support services including troubleshooting and tutorials. The Houdini tool is also enabled to offer what the Cinema 4-D and Blender can offer, however, the tool's license costs very high. The LightWave 3-D is another well-known tool for its easy workflow integration and ease of use. The animation performance of both the Animatron and Tumult Hype tools are similar in many ways, such as animation fidelity, quality of support, level of difficulty, and excellent workflow integration. For the AE applications, the Cinema 4-D animation tool has unique simulation, dynamics visual effects that are helpful to produce handsome vehicle-related animations based on physics principles with the minimum required skills. Also, the Cinema 4-D relies on the third-party plugins, such as $x$-particles, to animate combustion (fire effects), smoke, and fluid dynamics. Still, the Blender software is superior in fluid dynamics.

When it comes to interactive-user-based animations, traditionally, the programming languages, given in Table III, such as $\mathrm{C}$ and $\mathrm{C}++$, are very powerful in terms of design capability and workflow integrations. However, expertise in coding is required. Among all programming languages, the JS is proposed for its significant design capability and animation fidelity. This programming-based tool can also advantage from add-ons like Hover Effects for adding some more features. For short animations, the HTML5 through WebGL or
CSS3 has several advantages, such as box model, image values and replaced content, text effects, backgrounds and borders, better animation capability, user interface, multiple column layouts, and 2-D/3-D transformations. This tool is a very good candidate when the designer can benefit from many online platforms, such as the HTML5 maker, to design the animation content. Note that one of the main advantages of programming languages (underlined in the table) is being opensource and, thus, free of any cost for the users. To use any programming languages, listed in Table III, the level of coding knowledge is the key, regardless of the expertise, the JS programming language has been developed with an excellent feature for animation purposes. For example, the objects can be animated at the same speed using JS, without being affected by varying frame rates. Traditionally, the speed of some programs, such as $\mathrm{C}$ and $\# \mathrm{C}$, was dependent on the speed of the computer processor. An object could move across the screen a certain number of pixels every frame. If the processor could only run a game at 15 frames per second, and an object is programmed to move 10 pixels to the left at every frame, said object will move at 150 pixels per second. For instance, what happens if a different processor can run the animation at 60 frames per second, in that case, the designed object would move at 600 pixels per second. As a result, the JS-based animations have shown better compatibility with mainly online platforms, such as browsers and canvas.

Tables I-III were reported and compared based on the authors' experience and public user reviews given in [22]. Such labeling relies purely on how powerful the tools and coding languages are for users and animation designers. In terms of commercial tools, the more libraries, apps, add-ons, and tutorials are developed, the better the user experience could be seen. Another important factor is free of charge accessibility, for example, Blender has become very popular due to the fact that it is an open access (O.S.) tool. Hence, many experts in the field have developed library 
and add-ons which enrich the whole experience working with this software. In terms of programming language, JS is proposed because of high animation fidelity, which refers to how good the animation can perform under different harsh environments such as Internet latency. JS animations have been used by many people on online platforms, because of their time-based programming capability which brings a high-fidelity rate to demonstrate the animation aligned with the goals defined. Additionally, JS-based recently developed visual effects apps, which supported designers to produce medium/high visual-effects animations. The green color represents the advantages and the red color indicates the disadvantages.

Fig. 3 illustrates an example of animation for HEV power flow, where the operational five different operational modes can be selected for a front-wheel passenger car. As presented, the vehicle power distribution under $20 \%$ uphill is shown in both 2-D and 3-D using Blender software. In Fig. 3(a), the HEV is presented for the uphill driving mode with a $20 \%$ road gradient, under such conditions, the powertrain consumes heavily and that is where both energy sources (battery and diesel) were continuously consuming energy. Both ICE and e-Motor are actively operating to overcome resistive longitudinal dynamic forces. Under urban cruising, the vehicle power demand is considerably dependent on the electric units (battery and e-Motor), as shown in Fig. 3(b). In this driving condition, mostly, the demand torque and speed are provided by the e-Motor and, thus, the fuel-based (in red) components are considered deactivated. Fig. 3(c) exhibits a $20 \%$ downhill driving mode, where a high level of regenerative power occurs. The regenerative braking system is an energy recovery mechanism lower down the HEV via converting its kinetic energy into a form that can be either used immediately or stored until needed. In the power regenerative mechanisms, the e-Motor benefits from the vehicle's momentum in order to recover energy, which otherwise would be lost to the brake discs as heat. Hence, a very low level of positive acceleration can often be predicted, that is why the ICE is assumed deactivated. In Fig. 3(d), the vehicle is considered under pure braking conditions, which often happens during urban driving. Under positive acceleration, the e-Motor draws power from the battery pack to produce torque and speed which eventually turn the wheels, creating the kinetic energy it requires to move. When the brakes are applied, also known as negative acceleration or deceleration, however, the process shifts into a reverse working mode. In negative deceleration, the kinetic energy, which was initially consumed to propel the vehicle, now makes the wheels rotate the e-Motor, turning it into an electric generator. Instead of consuming power, the motoring/generating begins generating energy from recuperating braking, using the vehicle's kinetic energy. The generated energy can be stored in the battery to maximize the vehicle battery efficiency. Under motorway between $50-70 \mathrm{mph}$, the vehicle uses both energy resources, diesel and battery, to propel the HEV. When the vehicle is cruising the power, demand is mostly offered by the battery and e-Motor and, therefore, it is presented that the red arrows are smaller in Fig. 3(e). The ICE's contribution would be very important when the
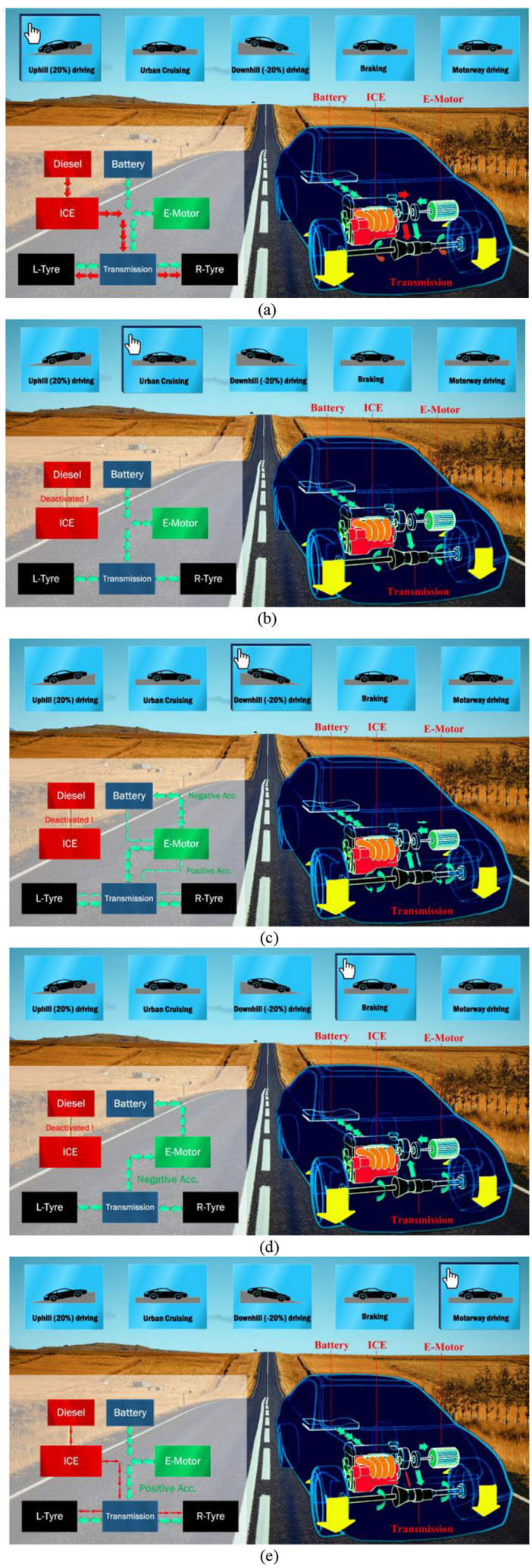

Fig. 3. Example of interactive animation for power distribution in HEVs under different driving modes: (a) 20\% uphill driving, (b) urban cruising, (c) 20\% downhill driving, (d) braking, and (e) motorway driving.

vehicle needs a large positive acceleration to reach top speeds; when the red arrows become slightly larger than the green ones. 


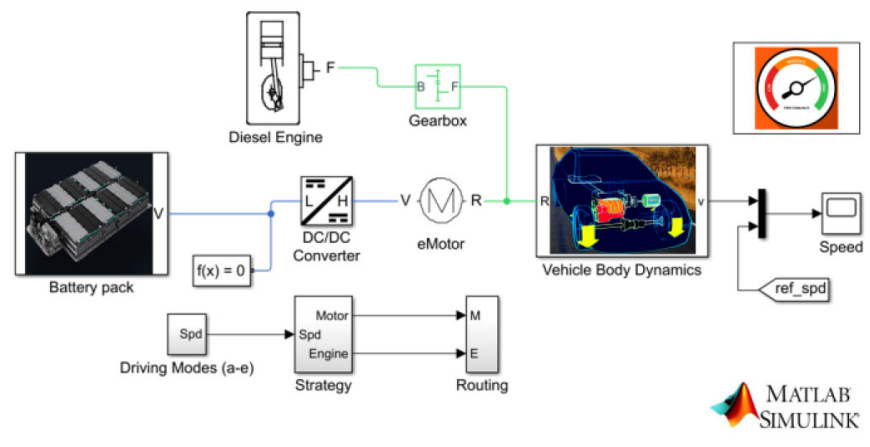

Fig. 4. Example of HEV powertrain modeling, in the MATLAB Simulink environment, using e-motor and ICE as traction units.

\section{Evaluation Process And ANALytics}

In this methodology, the students were introduced to illustrative and interactive animations weekly for a better understanding of the lecture/tutorial each week. For the presented animation introduced in Fig. 3, the effectiveness and evaluation of the cohorts are structured as below.

Step 1: Presenting the HEV powertrain configurations and building the models, see Fig. 4, based on the equations given, for example, for vehicle dynamics, battery, e-Motor, ICE, etc., the students are expected to understand the power flow within the vehicle, and eventually be able to expand the numericalbased models.

Step 2: Demonstrating the interactive animations for helping the students to gain a cognitive process understanding for utilizing such multiphysics-focused equations, which were discussed in step 1.

Step 3: Delivering assignments about the HEV modeling using different vehicle specifications under various predefined driving modes, meaning that the vehicle should be simulated under a user-defined drive cycle. Fig. 4 presents the HEV modeling assignment, in which the students can model and evaluate the powertrain design. In this model, the vehicle body dynamics contains all the longitudinal dynamics-based equations, the vehicle should satisfy the user-defined drive cycle under different driving conditions, such as uphill, cruising, motorway, etc., such modelings help students to learn how to select the optimal size of the battery pack, e-Motor/s, and ICE.

Step 4: Final exam and assignment submissions for the entire module. The final marks are recorded for statistical analysis and evaluation.

In this section, some straightforward questions, in the format of the survey, are asked at the end of the semester from the $\mathrm{AE}$ students, in the automotive electrical systems modules, and $\mathrm{AE}$ academics. The total population size of levels 5 and 7 students is 30 (from which 30 students participated) and 152 (from which 125 students participated). Both modules are accredited for 15 credit points. From all the AE academics, 12 members, all have participated in the questionnaire. Note that levels 5 and 7 refer to second year and first year students for undergraduate (or bachelor's degree program) and postgraduate (or master's degree program), respectively.
TABLE IV

Confident Level and Margin of ERror Based on THE SURVEY DATA

\begin{tabular}{c|c|c|c|c}
\hline \hline & \multicolumn{4}{|c}{$\begin{array}{c}\text { Confident level = 99\% } \\
\text { Margin of error }\end{array}$} \\
\hline participants & $\mathbf{1 5 \%}$ & $\mathbf{1 0 \%}$ & $\mathbf{5 \%}$ & $\mathbf{1 \%}$ \\
\hline 30 (undergraduate) & 22 & 26 & 29 & $\underline{30}$ \\
125 (postgraduate) & 50 & 80 & $\underline{124}$ & - \\
12 (academics) & 11 & 12 & 12 & $\underline{12}$ \\
30 (undergraduate) & 18 & 24 & 28 & $\underline{30}$ \\
125 (postgraduate) & 34 & 60 & $\underline{110}$ & - \\
12 (academics) & 10 & 11 & 12 & $\underline{12}$ \\
\hline \hline
\end{tabular}

The survey's sample size is calculated based on

$$
\text { Sample size }=\frac{z^{2} \times p(1-p) / e^{2}}{1+\left(z^{2} \times p(1-p) / e^{2} N\right)}
$$

where $z$ is (confident level) the number of standard deviations, $p$ is the percentage value in decimal, $e$ is the margin of error in decimal, and $N$ is the population size. Using (1), the confident level of the survey is reported in Table IV, where a very significant low level of error exists. Based on the participation, the maximum confident level of $99 \%$ with a minimum $1 \%$ margin of error can be reported for both the automotive electrical system module (undergraduate or level 5) and the $\mathrm{AE}$ academics associated data, however, the insufficient data from the automotive electrical system module (postgraduate or level 7) has resulted in approximately $99 \%$ confident level at 5\% margin of error. Note that the underlined numbers represent the taken margin of error for each confident level and group.

Before the investigation, the student's background and familiarity with automotive electrical systems were systematically considered. However, the methodology was limited in terms of what level of previous experience the students have had with this type of technology. From the data collected, some analytics and discussion have been provided. As presented in Fig. 5, the questions from both undergraduate, Fig. 4(a) and (c), and postgraduate, Fig. 4(b) and (d), students are as follows.

Q.1: In the online learning environment, do you prefer to be introduced to real-world equipment/devices and technology using animations or traditional approaches such as video recordings?

Q.2: What is the role of animation in online learning via virtual platforms like Canvas during COVID-19?

The AE academics also have participated in the questionnaire, where they responded to questions Q.2 and Q.3.

Q.3: How impactful animations are in your teaching experience in comparison to traditional theoretical-based-alone lectures and tutorials?

To highlight the student's performance within the use of animations in teaching materials, a failure per population (FPP) ratio is proposed to calculate another factor based on the student's reflection. The formula calculated the average value of FPP from 2012 to 2019 , then offers a decreased percentage in 


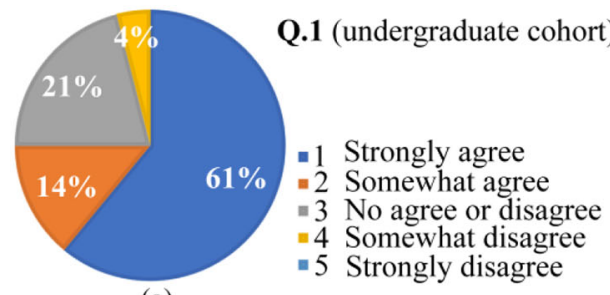

(a)

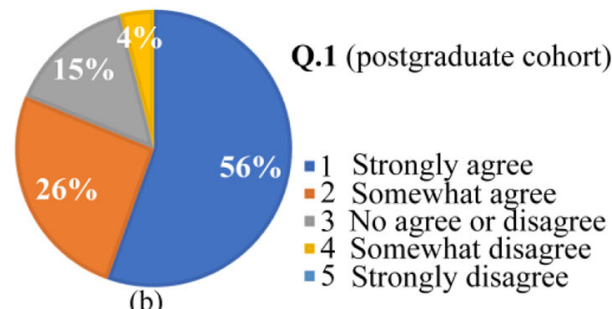

(b)

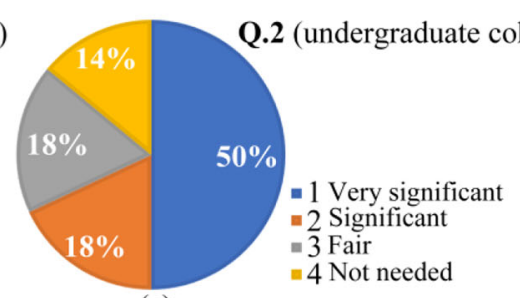

(c)

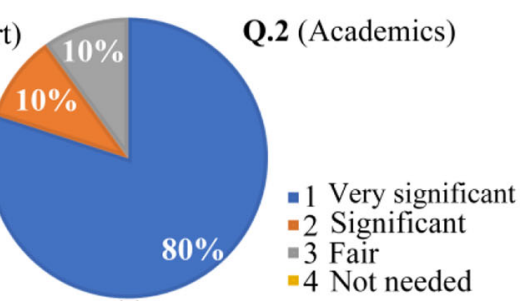

(e)

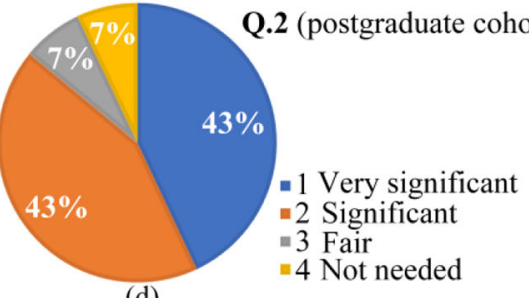

(d)

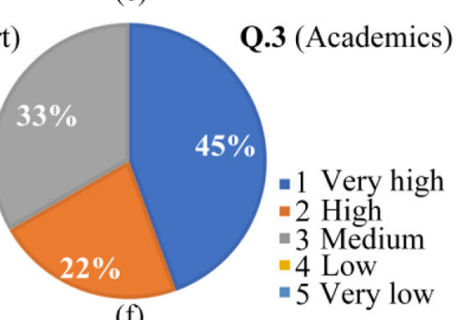

(f)

Fig. 5. Survey responses in percentage, based on the following questions. (a) Q.1 from undergraduate, (b) Q.1 from postgraduate, (c) Q.2 from undergraduate, (d) Q.2 from postgraduate, (e) Q.2 from AE academics, and (f) Q.3 from AE academics.

comparison to 2020. To calculate improved FPP in percentage

$$
\begin{aligned}
\mathrm{FPP}_{y_{1}} & =\frac{\frac{\sum_{i=y_{1}}^{y_{2}-1} x(i)}{\text { Total number of years-1 }}}{\text { Total Population of Students }^{\mathrm{FPP}_{\text {improved }}}}=\left(\frac{\mathrm{FPP}_{y 1}-\mathrm{FPP}_{y 2}}{\mathrm{FPP}_{y_{1}}}\right) \times 100
\end{aligned}
$$

where $x$ is the FPP for each year, $y_{1}$ and $y_{2}$ are minimum (2012) and maximum (2020) number of years in the study, which is 2012 to 2020 in this study. Using (2), the rate of failure is considerably improved by minimum $18 \%$ for both cohorts.

As reported in Fig. 5, most of the undergraduate students have strongly agreed by $61 \%$, and another $14 \%$ somewhat agreed, that the need of having animations is helpful for a better understanding of AE concepts, particularly in the form of online learning platforms. On the other hand, the postgraduate students postgraduate feedbacks explain that about $75 \%-81 \%$ of students are reacted considerably positive toward using animations in the classrooms. Although, $11 \%$ is not very significant by $56 \%$ (strongly agree) and $26 \%$ (somewhat agree) have responded to similar questions. Hence, both undergraduate and percentage, yet the student's learning experience and satisfaction can be penalized when they must take their modules entirely online. From the second question, the online platforms are determined unavoidable for both levels by $68 \%$ and $86 \%$ (very significant and significant), and, the AE academics by $90 \%$. The survey indicates that the student's appetite for animations is also considerable for regular classrooms, not only virtual classrooms.

Fig. 6 demonstrates the historic final marks for the related quiz from 2012 to 2020 . While the bars represent up to $75 \%$ of the grade's concentration, the horizontal line in the middle of each bar presents the average grade of the class. Fig. 6(a) and (b) reports the increased average mark of $28 \%-30 \%$ for both undergraduate and postgraduate cohorts. The full year-toyear comparative students' outcome is reported in Table V. In overall, the average marks of both undergraduate and postgraduate modules are improved within the year of 2020. Also, the

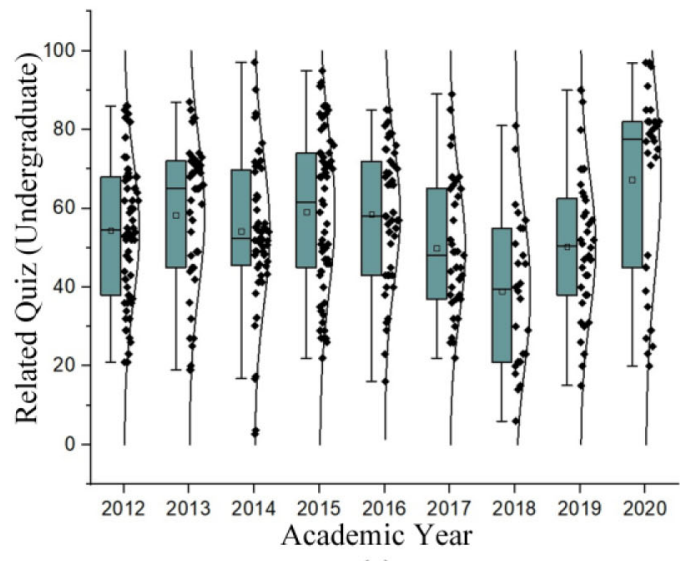

(a)

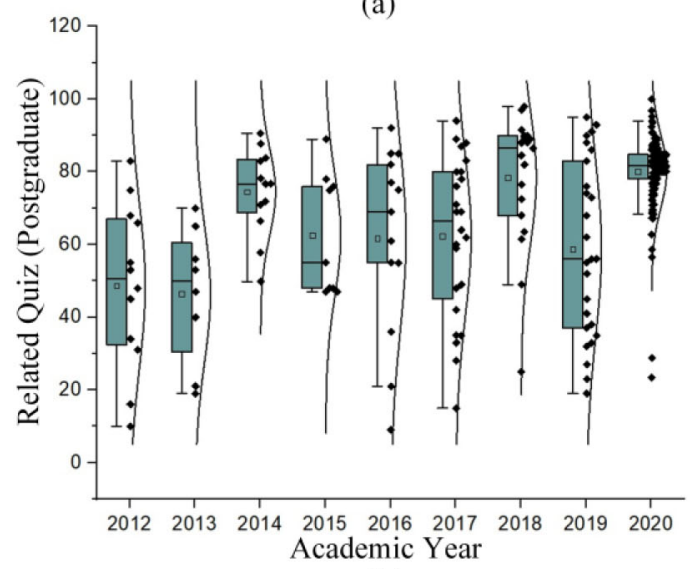

(b)

Fig. 6. Historic final marks for the related quiz per academic year for both (a) undergraduate (or level 5) and (b) postgraduate (or level 7) cohorts.

FPP rate has remained low, if not the lowest. It should be also mentioned that the number of students dropping out (DPO) the exams per population is the lowest for both modules in 2020. The study targeted the application of interactive animations in engineering curricula, in which a strong link between cognitive understanding, modeling, and simulation exists. This 
TABLE V

Historic Student Performance Considering FPP Rate

\begin{tabular}{l|cccc}
\hline \hline $\begin{array}{l}\text { Performance/y } \\
\text { ear }\end{array}$ & \# of students & average mark & FPP & DPO \\
\hline \multicolumn{5}{c}{ Undergraduate level 5 (second year of BEng program) } \\
2012 & 63 & 54.40 & 0.26 & 4 \\
2013 & 45 & 58.25 & 0.16 & 2 \\
2014 & 57 & 54.19 & 0.12 & 2 \\
2015 & 61 & 59.01 & 0.18 & 1 \\
2016 & 46 & 58.53 & 0.13 & 1 \\
2017 & 39 & 49.89 & 0.30 & 3 \\
2018 & 26 & 38.88 & 0.52 & 4 \\
2019 & 37 & 50.33 & 0.27 & 4 \\
2020 & 31 & 67.23 & 0.20 & 0 \\
\multicolumn{5}{c}{ Postgraduate level 7 (first year of MSc program) } \\
2012 & 13 & 48.67 & 0.33 & 0 \\
2013 & 9 & 46.37 & 0.25 & 1 \\
2014 & 13 & 74.47 & 0.00 & 0 \\
2015 & 10 & 62.55 & 0.00 & 0 \\
2016 & 14 & 61.69 & 0.23 & 0 \\
2017 & 25 & 62.25 & 0.20 & 3 \\
2018 & 20 & 78.42 & 0.05 & 1 \\
2019 & 27 & 58.76 & 0.31 & 0 \\
2020 & 153 & 80.14 & 0.01 & 0 \\
\hline \hline
\end{tabular}

cycle could result in a different range of students' outcome in both modules. As presented in Fig. 6, the postgraduate average mark was reported considerably higher than the undergraduate cohort, the main reason is that postgraduate students have a more mature understanding of how powertrains work, in addition to, more experienced hands-on modeling and simulation skills. On the other hand, the HEV powertrain concept and theory is a brand-new concept for junior students (level 5).

\section{CONCLUSION}

The idea behind using more animations in engineering curricula is to improve cognitive process understanding for utilizing such multiphysics-focused equations into a pragmatic dimension. This article studied the impact of both illustrative and interactive animations, using capability analysis of the existing computer-aided tools, for mainly AE concepts. This analysis offers an overview of the latest technological tools, including commercial and programming-based platforms, to support HE educators to use illustrative and interactive animations in their teaching contents which increases the students learning experience and satisfaction. Among them, the Blender and Cinema 4-D commercial tools, and JS programming language are proposed due to considerable features and design capabilities. Based on a quantitative survey from two cohorts, of undergraduate and postgraduate in automotive electrical systems module, the students have shown $(75 \%-81 \%)$ a surge of interest in animations. This is pertinent considering the increasing overall marks $(28 \%-30 \%)$ of students and improved FPP by a minimum of $18 \%$, because of several factors, such as better understanding and learning experience. The main research contributions of this study can be listed as follows.
1) Technical fidelity and overview of several illustrative and interactive animation tools, which provide capabilities for producing animations for engineering modules.

2) Producing illustrative and interactive animations using the proposed tools for AE modules alongside MATLAB Simulations for better understanding, which presumably offers a cognitive process understanding for utilizing such multiphysics-focused equations into a pragmatic dimension.

3) A survey-based study to evaluate the effectiveness of using animations on weekly basis, this section of the study has offered statistical-focused comparisons to validate the impact of computer-aided techniques in $\mathrm{HE}$ curricula.

The study was limited in: 1) evaluating the students' previous experience in learning using animations; 2) incorporating additional data collected over a few years with an online/hybrid teaching approach; 3) studying if the interest of students sustained throughout the semester by taking surveys at multiple points during each semester; and 4) requesting students' feedbacks for areas of improvement or where they fill the animation tools can fill a learning gap. For future investigation, the authors will consider the above-mentioned limitations 1)-4), developing and presenting more illustrative and interactive contents, where a learning gap exists for the coming years.

\section{REFERENCES}

[1] R. C. Schank, M. Korcuska, and M. Jona, "Multimedia applications for education and training: Revolution or red herring?" ACM Comput. Surveys, vol. 27, no. 4, pp. 633-635, 2016.

[2] N. D. Finkelstein et al., "When learning about the real world is better done virtually: A study of substituting computer simulations for laboratory equipment," Phys. Rev. Sci. Technol. Phys. Educ. Res., vol 1, pp. 1-8, Oct. 2005.

[3] A. Kohnle, M. Douglass, T. J. Edwards, A. G. Gillies, C. A. Hooley, and B. D. Sinclair, "Developing and evaluating animations for teaching quantum mechanics concepts," Eur. J. Phys., vol. 31, pp. 1441-1455, Nov. 2010.

[4] R. Pinter, D. Radosav, and S. M. Čisar, "Analyzing the impact of using interactive animations in teaching," Int. J. Comput. Commun. Control, vol. 7, no. 1, pp. 147-162, 2012.

[5] K. Ferens, M. Friesen, and A. Ingram, "Impact assessment of a microprocessor animation on student learning and motivation in computer engineering," IEEE Trans. Educ., vol. 50, no. 2, pp. 118-128, May 2007.

[6] S. Djenic, R. Krneta, and J. Mitic, "Blended learning of programming in the Internet age," IEEE Trans. Educ., vol. 54, no. 2, pp. 247-254, May 2011.

[7] Q. Jian, "Multimedia teaching quality evaluation system in colleges based on genetic algorithm and social computing approach," IEEE Access, vol. 7, pp. 183790-183799, 2019.

[8] L. P. Rieber, "Effects of visual grouping strategies of computer-animated presentations on selective attention in science," Educ. Technol. Res. Develop., vol. 39, pp. 5-15, Dec. 1991.

[9] R. E. Weiss, D. S. Knowlton, and G. R. Morrison, "Principles for using animation in computer-based instruction: Theoretical heuristics for effective design," Comput. Hum. Behav., vol. 18, pp. 465-477, Jul. 2002.

[10] R. Moreno, "Optimising learning from animations by minimising cognitive load: Cognitive and affective consequences of signalling and segmentation methods," Appl. Cogn. Psychol., vol. 21, pp. 765-781, Sep. 2007.

[11] D. A. S. Maria, G. A. Cayetano, and M. T. H. Francisco, "E-learning multimedia applications: Towards an engineering of content creation," Int. J. Comput. Commun. Control, vol. 3, no. 2, pp. 116-124, 2008. 
[12] W.-F. Kent Fuchs, W. Page, H. J. Patel, and P. Tobin, "Workstationbased logic animation and microarchitecture emulation for teaching introduction to computer engineering," IEEE Trans. Educ., vol. 32, no. 3, pp. 218-225, Aug. 1989.

[13] S. Robbins and K. A. Robbins, "A microprogramming animation," IEEE Trans. Educ., vol. 41, no. 4, pp. 293-300, Nov. 1998.

[14] A. A. Rodriguez, R. R. Metzger, O. Cifdaloz, and T. Dhirasakdanon, "Description of a modeling, simulation, animation, and real-time control (MoSART) environment for a class of electromechanical systems," IEEE Trans. Educ., vol. 48, no. 3, pp. 359-373, Aug. 2005.

[15] R. Abreu, and J. A. F. D. Santos, "Using abstract anchors to aid the development of multimedia applications with sensory effects," in Proc. ACM Symp. Doc. Eng., vol. 2, 2017, pp. 211-218.

[16] J. Shuja et al., "Towards native code offloading based MCC frameworks for multimedia applications: A survey," J. Netw. Comput. Appl., vol. 75, pp. 335-354, Nov. 2016.

[17] J. Bourne, D. Harris, and F. Mayadas, "Online engineering education: Learning anywhere, anytime," J. Eng. Educ., vol. 94, no. 1, pp. 131-146, 2005.

[18] D. Xu and S. S. Jaggars, "Performance gaps between online and face-toface courses: Differences across types of students and academic subject areas," J. High. Educ., vol. 85, no. 5, pp. 633-659, 2014.

[19] P. C. Holzweiss, S. A. Joyner, M. B. Fuller, S. Henderson, and R. Young, "Online graduate students' perceptions of best learning experiences," Distance Educ., vol. 35, no. 3, pp. 311-323, 2014.

[20] P. J. eMartínez, F. J. Aguilar, and M. Ortiz, "Transitioning from face-toface to blended and full online learning engineering master's program," IEEE Trans. Educ., vol. 63, no. 1, pp. 2-9, Feb. 2020

[21] Vimeo. (2018). Datos Formula 1 México. [Online]. Available: https://vimeo.com/279940693

[22] (2021). Online Software Reviews. [Online]. Available: https://www.g2.com/

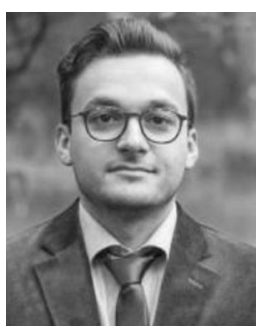

Pedram Asef (Senior Member, IEEE) received the B.Sc. degree in electrical engineering from Shiraz University, Shiraz, Iran, in 2012, the M.Eng. degree from the Huazhong University of Science and Technology, Wuhan, China, in 2015, and the Ph.D. degree (cum laude) in electrical engineering from the Universitat Politècnica de Catalunya-BarcelonaTech, Barcelona, Spain, in 2018.

$\mathrm{He}$ is a Lecturer (an Assistant Professor) of Automotive Engineering specializing in Automotive Electrical and Electromechanical Systems with the Department of Engineering and Technology, University of Hertfordshire, Hatfield, U.K. His previous and/ or current projects were funded by the European Space Agency, UKRI, European Commission, and Texas State Center for Port Management. He has published more than 20 research papers at international conferences, journals, and registered two patents. He is the Academic Advisor for the UH Eco Racing team, responsible for designing, building, and racing an energy-efficient car in the annual Shell Eco-marathon competition. His research interests include electrical machines and drives, automotive electrical systems, optimization methods, transportation electrification, and renewable energy systems.

Dr. Asef has been the Lead Representative of the IEEE Power and Energy Society, Young Professionals, in Europe Region, since 2018. He is the chair and/or committee member of several IEEE international conferences every year. $\mathrm{He}$ is also an editor for multiple indexed international journals in the field. He is a Fellow of Higher Education Academy and a Charted Engineer registered by Engineering Council.

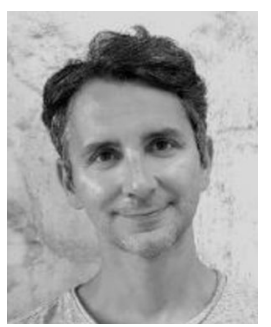

Christos Kalyvas received the Ph.D. degree from the Department of Chemical Engineering, Imperial College London, London, U.K., in 2005.

In 2006, he joined Prof. Nigel Brandon's Research Group, Imperial College London, as a Research Associate and specialized in fuel cell science and engineering. As part of this appointment, he worked on various fuel cell research projects in collaboration with industrial partners, such as Rolls Royce, Ceres Power, and Johnson Matthey. From 2012 to 2014, he led the proof-of-concept research on an innovative fuel cell stack architecture based on the use of printed circuit board technology. This project resulted in the PCBFC fuel cell technology and the creation of the spin-out company, Bramble Energy in 2017. In 2015, he was appointed a Lecturer of Automotive Engineering with the University of Hertfordshire, Hatfield, U.K. He has published over 25 journal and proceedings articles. His primary research interests include, design and development of hybrid energy storage systems for electric vehicles \& UAVs, development of polymer electrolyte fuel cells for automotive applications, study of fuel cell degradation, development of thermo management systems of battery packs, as well as thermal modeling of lithium ion batteries employing phase change materials.

Dr. Kalyvas was awarded a three-year EPSRC/NPL Postdoctoral Fellowship to continue research work at Imperial College London a project that aimed at the development of a diagnostic instrumentation to study operation, performance and cell longevity of energy storage devices (i.e., fuel cells and battery cells) in 2010. In 2016, he and his M.Sc. student were awarded a UH Flare Ignite prize for the research study titled, "3-D thermal transient modeling of Li-ion battery packs for use in battery-powered personal rapid transit vehicles." He is an Associate Member of IChemE. 